Prynallt-Jones, K.A., Carey, M., and Doherty, P. (2017) 'Barriers facing social workers undertaking direct work with children and young people with a learning disability who communicate using non-verbal methods.' British Journal of Social Work Advanced access (online): February $4^{\text {th }}$. 


\section{Barriers facing social workers undertaking direct work with children and young people with a learning disability who communicate using non-verbal methods.}

\section{Katherine Anne Prynallt-Jones, Malcolm Carey and Pauline Doherty}

Abstract: This paper analyses data drawn from a small group of qualified social workers' specialising in work with disabled children who communicate using non-verbal methods. While a number of studies have criticised social services for neglecting disabled children, this paper re-evaluates evidence from the standpoint of a small group of experienced practitioners. Three substantive themes are explored which include: problems faced by practitioner's communicating with children and young people; barriers to direct work; and positive engagement or use of creative methods. Among other findings, the paper highlights the complexity of communication techniques when seeking to accommodate diverse service user and carer needs, as well as creative responses used by practitioners despite significant barriers that include limited available training, technology and financial resources. Despite policy initiatives and legal requirements emphasising the importance of direct work and participation with disabled children, the conclusion reiterates the narrow focus of current risk-averse social work around disability, as well a need for additional resources and training to improve relationships, communication and meaningful support for children and young people that meet basic legal requirements.

Keywords: care management; children; deskilling; learning disability; non-verbal communication; risk-aversion. 


\section{Barriers facing social workers undertaking direct work with children and young people with a learning disability who communicate using non-verbal methods.}

\section{Introduction}

The need for improved communication skills to enable social workers to engage in more effective direct work with children with a learning disability and/or who communicate nonverbally is widely recognised (see Ward et al, 2005; Taylor et al, 2015). Currently statutory social workers are subject to legal and policy requirements to communicate directly and effectively with children and young people (Lefevre, 2013). In Britain, this includes expectations to inform, involve and consult with children who are in care (Blewett et al, 2007), an obligation reinforced within The Children Acts of 1989 and 2004 (Smith, 2009) and more recently Working Together Guidance (HM Government, 2013) and the Children and Families Act (2014). Such statutes outline that assessments must be informed by the wishes of the child, alongside the views of their family. The United Nations Convention on the Rights of the Child (UNCRC) also included two specific rights relating to listening to the voice of the child, which Lundy and McEvoy (2012: 130) affirm requires a 'concomitant duty on adults working with them to ensure that their right to express their views and influence their own lives is respected'.

Clare \& Mevik, (2008), nevertheless, argue that social workers' direct practice with children and young people currently falls short of many basic legal requirements as well as the expectations of many children and families. For example, the Munro Review of Child Protection (2011) maintained that there continues to be a lack of meaningful relationships between social workers and children, which can significantly hinder the work of social care professionals and potentially place children at risk. Advocates such as Morris (2005) have reiterated that social exclusion is often most prevalent for disabled children in care. Too 
frequently poor relationships, inconsistent support or protection - alongside long-held 'deficit thinking' supposed within reductive or binary discourses of normality and difference - persist from welfare professionals (including social workers) which further disadvantages the life chances of many disabled children. Following reductions in formal support as part of ongoing austerity policies within Britain, minimal care and service provision has often been provided. This has tended to prioritise the management of 'high risk' alongside the subtle promotion of independence, autonomy and self-support for children or young adults whose needs are not unusually dismissed as being 'non-critical' (Goodley, 2013; Oliver, 2013)

This paper draws from a study of a small group of qualified social workers who specialise in work with children and young people with a learning disability and/or additional needs. It draws upon interviews with practitioners to explore communication and other potential obstacles faced in work with disabled children who communicate using non-verbal methods. This is achieved by examining three related and substantive areas of analysis which include: i) Problems with communication; ii) Barriers to direct work; and finally; iii) Positive engagement and use of creative methods. Whilst some previous studies have understandably tended to prioritise the multiple forms of disadvantage experienced by disabled children - including a lack of appropriate care from social workers - this paper seeks to re-examine this evidence from the standpoint of practicing social workers. Among other findings, it highlights the complexity of communication amidst diverse service user and carer needs, alongside some attempts made by professionals to achieve creative responses despite significant barriers faced which include extremely limited available training and resources. The conclusion draws from the data and other studies to emphasize the many structural and organisational obstacles faced by social workers; alongside the need for improved training, additional resources and greater support in order for staff to be able to meet many of their basic legal requirements. This includes the promotion of active participation and inclusion for disabled children and young people. 


\section{Some problem of communication or engagement within social work and learning disability services}

Direct work is defined as entering a child's world to enable them to understand significant events in their past and current situation, alongside a preference given to listening to their views (Horwath, 2010). According to Wyse (2004) communicating with children involves many and sometimes distinct yet complex interrelated skills which can include: maintaining autonomy or sharing a positive understanding, building trust, sustaining a good rapport and empathy alongside an ability to work or talk at the child's level. A capacity for interpersonal skills such as drawing and play again remain important traits. Fahlberg, (2012) adds that a key aspect of direct social work is listening to and observing children in multiple environments.

Holland (2011) has proposed that disabled children who express their views non-verbally can be underestimated by professionals, many of whom relate solely to verbal means of expression. In relation, Thomas (1999: 42-43) has introduced the concept of 'psycho-emotional disablism' to distinguish the ways by which restrictions may be imposed on children who have a physical, sensory or learning impairment. This may include disabling assumptions or situations imposed by family members, professionals and others. Such discrimination may exist in parallel to traditional notions of material and structural exclusion prioritised within social models of disability (for example, Oliver, 2013). Principally, Thomas draws a distinction between barriers to 'doing' and associated impediments to 'being', with the latter emphasising the management of personal identity, emotional well-being and social relationships. Despite the importance of professionals and others respecting each, it is often being-related needs which are overlooked.

Singh and Ghai (2009: 132-133) highlight that professionals often assume that children with learning disabilities have a 'unitary identity' which may lead to a 'denial of other significant aspects of their experience'. Corker and Shakespeare (2002) note the increasing influence of 
the medical model of disability within wider welfare professions, including its separation from 'non-disability' and 'normalcy' alongside an implicitly assumed stress upon what is lacking, tragic or even deviant. Read et al, (2009) add that disabled children from minority ethnic groups not untypically encounter more intense forms of discrimination from professionals.

As part of a critical appraisal into children's services, Stein (2009: 99-101) argues that social workers may passively assume that disabled children are not capable of understanding or expressing their views. Moreover when engagement and participation are evident this tends to be extremely variable between localities, as well as limited in many. Holland (2011) and Parton (2014), however, highlight the tensions which may quickly emerge between a complex role, in which good communication with service users and carers from diverse backgrounds remains a basic prerequisite, and seemingly relentless organisational pressures to adhere to more limited managerial and bureaucratic agendas.

Morris (2005: 25) maintains that disabled children have a greater need to be consulted by professionals such as social workers, due to the complexity of their needs alongside higher levels of social care intervention that some receive. This is of particular concern for disabled children in residential care, who are more vulnerable to abuse, and whose cognitive or communication impairments may make disclosures difficult to articulate. Intense financial restrictions and pressures - alongside implicit professional prejudice - may further restrict the likelihood of such children receiving appropriate care. Morris (2005: 24-26) goes on to highlight related problems of limited training available for social workers who work with children with a disability, alongside reduced numbers of experienced workers in a profession with an increasingly high turnover of staff, excess levels of bureaucracy, accountability and performance related targets, and limited available resources. Such obstacles can lead to social workers and others looking 'for ways to limit resources rather than for ways in which to meet children's needs'. 
Lishman, (2009) maintains that non-verbal communication is complex, difficult to translate and a clear understanding and knowledge base remain essential for professionals. While children with severe cognitive impairments or learning disabilities may have limited use of language, many communicate successfully using non-verbal and adaptable means. This can include symbols, objects, gestures, communication books or electronic equipment, to support their participation. Non-verbal communication remains an important element and is often a preferred method for many children with a learning disability. Read et al, (2009) maintain that multiple communication systems and varied media options provide enhanced opportunities to aid children's cognitive and social development, which can all provide an opening to participate in their world. Kirton, (2009), however, raises concerns of the potential risks surrounding the possible ambiguity and understanding of non-verbal communication and the context of the individual child. Marked inequalities and obstacles to socio-communication can persist between non-speaking children and speaking adults. This can include that many adults are more likely to limit, control and shape conversations, and misinterpret non-vocal or nonintelligible expressions of meaning (see, for example, Clarke and Wilkinson, 2009: 583-586).

Additional problems can persist during safeguarding assessments for social workers. These include that legal requirements generate tight timescales which can be difficult to meet with a non-vocal child. Moreover practitioners often lack confidence, have limited training or over rely upon parent or carer viewpoints. In some instances practitioners may inaccurately assume that parents are doing their best against great odds. In addition, elevated priorities concerning safeguarding and risk aversion will tend to be built around the needs of children without a disability (Edwards and Richardson, 2003). Miller and Brown (2014: 16-17) add that a child with a learning disability may not be fully aware of the meaning of abuse or neglect, have a limited circle of trusted adult contacts to communicate with and can feel anxious that they will 
lose the support of people who they rely on if they disclose too much information. Disabled children may also be unable to use technologies such as a telephone or the internet, including to report any instances of neglect or abuse.

\section{Methodology}

This research aimed to identify and better understand the experiences of a group of qualified social workers in their attempts to communicate with and support children and young people who have a learning disability and communicate non-verbally. It sought to recognise potential barriers which might limit the types of non-verbal communication utilised with disabled 'service users', as well as detect possible resources, if evident, that might enhance interaction and forms of meaningful engagement. Alongside thematic analysis, the methodology drew upon some core aspects of phenomenology: including its capacity to examine how people 'make sense of their major life experiences' (Smith et al, 2009: 1; Thorne, 2016). The researchers acknowledge that capturing and analysing experiential data is rarely clear-cut, and sometimes places the researcher (and researched) in 'precarious positions' including with attempts to collect a 'multiplicity of insights, perspectives, and approaches' so as to build meaningful and relevant understanding (Thorne, 2016: 11).

Interviews and analysis were used to encourage participants to discuss issues in their own frames of reference so to maximise the researchers' understanding (Smith et al, 2009; Smith, 2009). Interviews lasted up to one hour and each were recorded and transcribed. Stages of thematic analysis were developed to identify overarching themes in the data analysis process (Braun \& Clarke, 2006). Each theme was further divided into sub-themes and responses which were then colour-coded accordingly. A table of key words was then formed and coded to develop inter-connected pieces in the data. Broader themes then emerged by drawing the codes 
together, which created a concise format to display the findings so to support any further discussions made.

Ethical approval was gained for the research from an Ethics Committee within a University where the project was based. The research drew upon data collected during semi-structured interviews with a small convenience sample of qualified practitioners, alongside some ethnographic accounts following a six month period spent working alongside the practitioners. The social workers were based in a statutory Children with Disabilities Team (CWDT) located in North West England. The team undertook complex assessments and provided support, advice and guidance, alongside a range of services to meet the needs of children with disabilities and their families or carers. The casework undertaken by the social workers varied yet involved children with one or multiple of the following needs:

- Severe or profound learning disability- supported by a Statement of Educational Need;

- Severe physical disability;

- Substantial degree of visual impairment/ moderate, severe hearing loss or deaf;

- Complex Autistic Spectrum disorder with severe learning difficulty;

- Various complex medical health conditions.

Seven qualified social workers were interviewed, six were female and one male. Qualified experience in the team ranged from two to twelve years with an average of seven years across the sample. When direct quotations are used below, names have been changed to ensure anonymity but age and experience are accurate. 


\section{Findings and analysis}

\section{$\underline{\text { Problems with communication }}$}

All participants were experienced in non-verbal communication or used communication technologies such as the Picture Exchange Communication System (PECS) or Makaton in their direct work with children. However they were also keen to detail the importance of observations and facial expressions, alongside expressing simple and clear language or offering practical examples to children. This was not necessarily straightforward and might represent a challenge:

'It's mainly through observations of behaviour or facial expression, or if a child may make noises which will indicate if they are happy, sad or anxious' (Ruth, aged 48, 12 years' experience).

'We are often reliant upon interpreting body language, intermittent eye-contact, repeating sounds, which I find a real challenge'. (Amanda, aged 35, 12 years' experience)

It was identified that through casework children's levels of communication varied significantly which regularly added difficulties to professionals' ability to interpret their views. This was raised specifically with any child protection concerns. One social worker, for example, discussed the difficulties surrounding any possible allegations, as the child may not be able to communicate or understand any injury. This was further linked to the child's cognitive functioning and understanding;

'Normally you would go out and speak to the child, but I have found this very difficult as that child cannot tell you if there is an injury or something like that' (Anna, 32, 4 years' experience) 
Miller and Brown (2014: 16-17) surmise that when a child has a profound and multiple disability, professionals may not be proficient in understanding how the child 'communicates distress, anxiety and fear'. Indeed one response maybe to attempt to stop challenging behaviour rather than examine the underlying causes, despite this being a potential indicator of neglect or abuse. Despite this, one social worker interviewed was able to share many positive experiences as communication methods were of great personal interest. Liberators, sign language, PECS and symbols were used in her practice on a regular basis, alongside facilitating court work to allow deaf children's voices to be heard. Young et al's (2009: 4) survey of 57 Local Authorities' in England, however, discovered that broad-based disability children's teams' of social worker's tended to 'lack sufficient staff with the expertise and skills to accommodate deaf children's complex needs'. For example, limited specialist knowledge or expertise 'demonstrably hampered teams from being able appropriately to recognise the seriousness of a presenting problem when it concerned a deaf child'. Potentially this may support evidence suggesting that disabled children's experiences or needs may be viewed as universal or homogenous by some professionals, or become assimilated and generalised as part of general organisational processes. Taylor et al's (2015: 2) interviews with ten deaf and disabled adults who had suffered abuse as children underlined their invisibility to formal service processes and provisions, alongside the tendency for disclosures of abuse to be ignored or discounted. As the authors conclude, in 'some cases services were absent from their lives, in others, provision was inadequate or inappropriate'.

In this instance, most social work participants' believed they were able to maintain positive awareness and gained wide experience using a variety of communication methods to facilitate direct work, and to obtain children's wishes and feelings through practical and observational methods. It was evident that most of the social workers felt more positive with regard to their capabilities, and most insisted that they got by. Despite such claims, each practitioner also 
acknowledged that in the view of the diversity of needs and challenges faced communication continued to be part of a difficult process. Singh and Ghai (2009: 31) have argued that limited appropriate cultural values, expertise and subsequent support can promote a 'suspended' or 'eternal childhood' for many disabled children, which encroaches into adulthood. Goodley (2013: 72) adds the additional impact upon disabled children and adults of seemingly 'useless anti-discrimination legislation, inflexible employment laws and exclusionary educational policies and practices'. Concerns about the impact of wider structural exclusion also chime with critiques of social workers marginalising socio-economic factors during assessments and in their wider work with some children and families (see Cleaver et al, 1999; Parton, 2014).

\section{Barriers to Direct Work.}

Social workers were questioned about the potential barriers and challenges they encountered, especially whilst obtaining children's views during assessment processes. Five participants stated that the biggest barrier was the limited amount of time they had available to conduct assessments and gain a thorough insight into children's views. Alongside the common experiences of professionals working with non-disabled children (Ferguson, 2010; Munroe, 2011), all of the social workers interviewed felt that they carried excessive caseloads. Each also expressed concerns that they did not have the time to build relationships with children or to gain an adequate awareness of their full needs:

'To get the full picture, you need to take the time to know these children, more than just one snapshot assessment. To get a true understanding you cannot always gauge this from just one visit' (Paul, 31, 9 years' experience).

Taylor et al (2015) have argued that learning disability services including within social work increasingly lack meaningful engagement with disabled children. This makes attempts to fulfil holistic assessments and to fully appreciate the 'voice' of a child extremely challenging. 
Moreover, poor inter-agency communication and interventions are not uncommon outcomes which impinge upon attempts to adequately meet children's needs (Murray, 2000; Miller and Brown, 2014). One social worker, however, believed that in her current work environment she had gained more time in comparison to her previous work in a non-disability safeguarding team. Nevertheless, this additional time was still not considered to be enough since the practitioner felt that disabled children's needs often remain much more complex. In addition to the time element, bureaucracy was identified as representing a significant barrier, which seemingly continued to intensify (despite the recommendations of Munroe, 2011). Webb (2006: 141) has highlighted the escalating use of 'technologies of care' within social care fields, including the proliferation of risk assessments, information technologies and evidence-based practices. Each tends to compress meaningful social work activities, knowledge bases or skills into 'technical calculative forms' which 'objectively reframe clients' experiences'. Invariably complex social needs and interventions around learning disability or childhood may become decontextualized, processed and over simplified, whilst good relationships and communication are undermined. As one participant noted:

'We are bogged down with computer work and making sure everything goes on the computer, and some of the work you do with our children is difficult to capture on the systems we have. So we do get caught up all the time'. (Vicky, 44, 2 years' experience).

A lack of professional confidence was raised by three practitioners. This related to social workers having limited opportunities to develop their confidence to undertake direct work and deliver their skills into practice. It was believed that other professionals, such as teachers working with disabled children, had more opportunities to build relationships and practice their communication skills. Four social workers argued that their confidence and ability to undertake direct work could be strengthened by attending more regular training sessions. Limited knowledge gained and low self-esteem had generated anxieties or limited competencies for 
some, including personal capacities to achieve good communication with children. Such scenarios contrast with recommended cultures of practice which include a strong belief that understanding a disabled child's development regarding 'her/his sense of self would necessitate an abandonment of the view of 'disabled' children as a homogenous category' (Singh and Ghai, 2009: 131). As Goodley (2013: 72) adds, poor relations and limited communication risks damaging children with disabilities at the level of agency. For example, by promoting discrimination among professionals and within dominant discourses that may be 'felt relationally, psychologically and subjectively'.

Woodcock and Tregaskis (2008: 60) argue that social workers working with parents or carers whose children have a disability should 'move beyond their 'surface-static' perceptions of parenting as task-orientated and unchangeable' and towards understanding parenting as being 'fluid and variable over time and context due to the influences of social as well as individual factors'. We were, however, informed that not all parents or carers valued professionals who sought to build relations and gain their children's views:

'We actually have difficulties with parents accepting that you want the child's views, in reviews we encourage the child to attend yet the parents often say there is no point'. (Amanda).

It was noted, also, that some social workers felt that they relied too much upon parental or carer accounts rather than the perspectives of disabled children. Again this related to the restrictive timescales available during relatively brief meetings. Yet all of the social workers interviewed argued that the child's needs could become overlooked if adequate consultation did not take place:

'I think we can rely on parents or carers too much, to give you all the answers you need quickly, and in child protection cases this may not be the best way'. (Paul). 
Parental attitudes and involvement in the assessment processes was identified as paradoxical, as it could offer a rich source of vital information, yet also, alongside bureaucracy and limited training, meant that engagement with disabled children was typically further restricted.

It was collectively identified from the interviews that social workers could not ascertain any notable training around disability that they had received on their social work degree programmes, and that this highlighted a significant barrier to good practice. Attention, for example, has been drawn to the limited material on areas such as ageing and disability on many social work programmes, despite claims of course content being 'generic' (see Richards et al, 2013). Many authorities also now provide limited specialist training such as Continued Professional Development (CPD) for social workers working with disabled children (Doel et al, 2008; Ofsted, 2012: 5). Only two social workers commented that they had received basic training in British Sign Language, alongside a one day course on safeguarding disabled children, but it was noted that this was a long time ago and many methods and processes had since become dated.

Despite the lack of training identified in the team, three social workers felt that more was perhaps gained from actually undertaking direct work with children themselves and developing their skills together. Despite obstacles, opportunities available in team discussions and during informal training opportunities were acknowledged as helpful by two social workers. Discussions and ideas for communication skills had occurred within team meetings, as well as by co-working alongside other professionals and sharing knowledge and methods. Due to personal frustration some staff had also invested their own money and time;

'I have done a lot of my own learning, Makaton with the speech and language therapist, but there is not a lot out there in terms of specialist training and more is needed' (Amanda). 


\section{$\underline{\text { Positive engagement and creative methods }}$}

Social workers were questioned about the requirements needed to enable barriers identified to be overcome. Two participants argued that a comfortable and familiar environment would support disabled children to feel relaxed and secure whilst engaging with their social worker. In supporting Fahlberg's (2012) recommendations of utilising multiple environments, all of the practitioners stressed the importance of being able to visit children in a variety of settings, including the school, home and wider 'community' (see also Ferguson, 2010). This was recognised as being significant to bolster the assessment process as well as allowing an opportunity to build trust and potentially offer more coherent support (especially if adequate funding was available). The group emphasised that engagement in multiple settings with a child remained the only means by which to achieve a truly 'holistic' assessment.

Three participants commented that successful direct work is embedded in knowing the child's family and networking with multi-agency teams to draw upon their communication methods. Successes were also allied to creativity and the practical skills and pedagogical dispositions social workers used to elicit children's views. Three social workers raised the importance of using practical ideas to engage children and understand their thoughts, such as through artbased and sensory related activities. In support, Singh and Ghai (2009: 135) argue that disability for children as identity category remains 'multifaceted and fluid', and involves 'repeatedly evolving and transforming the self'. It should where possible include efforts to achieve a 'deeper, more nuanced understanding of the disabled experience', including from professionals in multiple settings that reflect a child's complex needs.

The availability of communication aids were discussed with professionals; to identify resource gaps and methods which support engagement with children, alongside how creative methods are incorporated successfully in their practice. Five participants acknowledged that there were 
resources available, such as PECS, communication packs, sensory toys and craft materials and the importance of incorporating each to aid communication with children. Yet, two social workers commented that resources were dated and needed to reflect technological equipment which children now use more regularly. For example, the use of iPads to create photo-books and PECS programmes were discussed by two participants as being helpful. Yet even the use of such device(s) had caused problems due to their limited availability:

"Everything needs updating... We were promised an iPad in the team, but this is based in another office and is not really accessible to us, so I was very disappointed...I have taken pictures of a young person in placement for his review; he chose the music and pictures to reflect his journey and this worked well'. (Amanda).

Yet one respondent commented that technological equipment could again generate a further barrier regards communication. This was especially due to a lack of available training and any related lack of confidence in utilising such devices during contact with children or young people. Likewise, two other professionals were frustrated with the general lack of accessible equipment, including during previous cases were there had been ongoing child protection concerns.

Alternative and creative methods such as using craft to draw pictures or emotion cards for children to select how they were feeling were identified by social workers as extremely helpful resources. Similarly role-play and improvisation were used by one social worker. Another social worker discussed work undertaken with a train set and highlighted that building upon the child's interests often provided a positive resource. Yet community based activities were only used by one professional to spend time with children: 
'It's just about spending time with the child, maybe going for a walk, or going to the park on the swing, or just sat on the beach touching the sand, just making use of what's out there'. (Ruth).

Improvisation and use of everyday objectives could again offer a vital resource:

'Pens in your bag, they might not be colourful but they really work'. (Amanda).

Two of the social workers interviewed, however, were not aware of any resources to use with children to ascertain their views. This appeared to confirm different levels of motivation and approaches utilised within the team. Moreover, restrictive timescales and other responsibilities regularly limited opportunities. Other resources were nevertheless drawn upon. For example, by offering new insight, reflection and professional development, one social worker felt that supervision could provide an effective resource for support:

'I haven't regularly used resources [previously], but I have now started, as I have learnt through reflection in supervision that they have helped me interact with the young person'. (Paul).

Although not always available to support engagement with disabled children, participants valued external services and professionals, such as advocates, signers or interpreters.

Accordingly, participants expressed mixed opinions in relation to the resources they had access to in the team. In the majority of cases, resources were recognised as beneficial, but practitioners differed in how they were utilised and limited time meant that engagement with resources was always restricted.

Despite such difficulties, all participants were able to share positive experiences they had gained through communicating and undertaking direct work with disabled children during key and regular activities such as assessments of need. Examples included building rapport, 
offering pedagogical support, providing children with an opportunity to express their viewpoints and gain their insights. In view of this, the majority of participants believed that despite a number of significant obstacles and difficulties service delivery had still showed some signs of improvement in recent years. For example, three social workers highlighted changing attitudes which included much greater attempts made by colleagues to improve children's participation and, where possible, provide a sense of empowerment:

'It's about raising the child's profile and advocating on their behalf, and getting the message out that they might not communicate like you or I verbally, but they are communicating'. (Ruth).

\section{Discussion}

The World Health Organization (2013) has argued that children with a disability remain among the most marginalised and susceptible populations in the world. Increased statutory and legal expectations for participative and more engaged forms of multi-professional support for such children - alongside international, academic and civic pressures to disseminate social and person-centred models of intervention - have asserted significant pressures upon local authorities and the social work profession. Extending the choices and 'active agency' of children, including through communication, is recognised as an 'intrinsic value like other human rights' whose consequences are 'significant both for the disabled child and society' (Olli et al, 2012: 794). Such expectations, however, have transpired alongside the shrinking of financial resources and added demographic and organisational pressures within welfare and care. Oliver (2013: 1026), for example, has noted that ongoing reductions in benefits for disabled people as part of now long-term austerity measures in Britain are justified according to a misguided rationale of giving more to users "who are severely impaired (and hence deserving) and not to those who are not'. In addition, differences are 'being used to slash 
[disabled peoples'] services' whilst many local authorities are now 'only providing services to those whose needs are critical'. Consequentially as in the cases examined in this paper, most if not all authorities and professionals elsewhere are unlikely to be able to meet their basic legal requirements regarding care and support relating to disability and childcare.

Horwath (2011: 1080-1083) has drawn from data collected from several focus groups of frontline social work staff ( $n=62$ ) based in England to highlight other barriers to engaging with both non-disabled and disabled children. These included organisational priorities given to New Public Management systems and targets which result in 'an overemphasis on timescales and form completion by both practitioners and supervisors', alongside the prioritising of risk management which often 'separates risk of harm from need'. For some practitioners a processdriven siege mentality has formed which negates against the interests of children:

Participants also used military language like 'fighting', 'siege', 'doing battle' and 'bombarded'...The battling day and night to be true to their professional selves was exhausting and some practitioners had given up the fight, as evidenced by some of the practices described in the study, such as going through the motions of 'seeing' the child and allowing recording forms and timescales to drive practice.

Knight et al's, (2006) interviews with practitioners have again revealed that most social workers regularly acknowledge the importance of listening to disabled children. Despite this, home visits were restricted due to timescale pressures and high caseloads which impaired relationships, alongside any ability to incorporate non-verbal communication methods into assessments. Assessments may also quickly become dominated by parent and carer viewpoints, which can convey to children that their perspectives have been misrepresented or ignored. As Olli et al (2012: 794) note, active agency through communication may be compromised due to 
children's restricted cognitive competence or assumptions that 'give adults the power to decide who can use [basic human] rights'

In view of such findings it is perhaps unsurprising that criticism has tended to be levelled at social services for neglecting the needs of disabled children, and fault lines have regularly been set at an organisational (or implicitly practitioner) level (for example, Miller and Brown, 2014). This research, however, suggests that such conclusions reveal only part of the story and that there continue to remain significant structural, economic and cultural obstacles which prevent social workers from fulfilling many of their basic legal obligations. These include to promote the 'voices' of children with a learning disability, apply social models of intervention (however defined), avoid or confront 'psycho-emotional disabilism', or, at times, offer minimum levels of contact and adequate support for children, alongside parents or care givers. Whilst the sample for this research was very small it was notable that each practitioner stipulated substantial barriers to their personal capacities to fulfil core legal and policy driven responsibilities. This included a paucity of available time to spend with children or families involved in casework or assessments - alongside limited resources and inadequate training which subsequently restricted any capabilities to fully appreciate new technologies when they were made available to improve communication with disabled children. In this instance, however, some practitioners also viewed parents or carers as restricting their attempts to communicate with children, although this might again be something which could be overcome with more available time, (pre and post-qualification) training or resources. Henderson and Forbat (2002), for example, have illustrated that care giving and parenting remain a part of complex and ever adapting cultural processes and social relations which necessitate good communication and dextrous skills. These include the ability on behalf of professionals within care to articulate forms of emotional labour, reciprocity and trust. 
It was also discovered during interviews that a greater focus was being placed within assessments and interventions upon medical and healthcare-related perspectives (for example, prioritising pathologies, symptom related incapacities, and so forth) and away from any traditional priority given to social related needs (housing, environment, financial needs, and so on) by some practitioners. Such bias may in future intensify further following the recommendations of the Children and Family Act 2014, and other legislation such as the Care Act 2014, which have strongly recommended much greater levels of integrated care in work with children.

More emphasis within resource allocation and time for staff was also being given to concerns that linked to adult safeguarding and risk management. Conversely, Henderson and Forbat (2002) argue that welfare should instead be built around tangible relationships and meaningful communication with users rather than narrow interpretations of 'care'. This research discovered that it is also time which remains one of the more valuable yet increasingly scarce resources for professionals in social work with disabled children. In particular, time to engage and build trust, understanding, empathy as well as utilise creativity in direct work with children with a learning disability who use non-verbal methods. Such complex, longer-term and perhaps more meaningful work is likely to assist professionals in attempts to better understand impairment, alongside any persistent obstacles faced by disabled children to their core identity related activities of 'doing' and 'being' (Erikson, 1980; Thomas, 1999; 2007). In close relation, additional available time (and resources) may help discourage professionals from subconsciously presuming invisible, stereotypical or unitary disability identities (see Goodley, 2013), or prioritising illness, abnormality and risk during brief formal engagements; or neglecting the impact of social class and structural disadvantage and exclusion on children and parents (see Morris, 2005; Goodley, 2013; Parton, 2014). Despite some evidence of legal rights being met and professional recognition of needs, at present such prerequisites towards 
promoting constructive social work, participation and meaningful communication (Lundy and McEvoy, 2012; HM Government, 2013; Lefevre, 2013) appear to be limited by significant obstacles which are likely to add further to the structural and cultural disadvantages faced by disabled children who communicate via non-verbal methods.

\section{References}

Adams, R. (2012). Working with children and families; knowledge and contexts for practice. Basingstoke, United Kingdom: Palgrave Macmillan

Blewett, J., Lewis, J., \& Tunstill, J. (2007). The changing roles and tasks of social work: A literature informed discussion paper. Retrieved from: scie.org.uk.

Boyden, J. and Dercon, S. (2012) Child Development and Economic Development: Lessons and Future Challenges Oxford, Department of International Development

Braun, V., \& Clarke, V. (2006). Using thematic analysis in psychology. Qualitative research in psychology, 3(2), 77-101.

Clare, B., \& Mevik, K. (2008). 'Inclusive education: Teaching social work students to work with children', Journal of Social Work, 8(1), 28-44.

Clarke, M. and Wilkinson, R. (2009). The collaborative construction of non-serious episodes of interaction by non-speaking children with cerebral palsy and their peers. Clinical Linguistics and Phonetics 23 (8): 583-597. 
Cleaver, H., Unell, I., and Aldgate, J. (1999) Children's needs - Parenting capacity: The impact of parental mental illness, problem alcohol and drug use, and domestic violence on children's development London, Stationery Office

Corker, M., and Shakespeare, T. (eds.) Disability and Postmodernity: Embodying Disability Theory London, Continuum.

Doel, M., Nelson, P. and Flynn, E. (2008). Experiences of post-qualifying study in social work. Social Work Education, 27 (5), 549-571.

Edwards, H. and Richardson, K. (2003) The child protection system and disabled children. In "It Doesn't Happen to Disabled Children": Child Protection and Disabled Children. Report of the National Working Group on Child Protection and Disability. London: NSPCC

Erikson EH (1980) Identity and the Life Cycle. New York: WW Norton \& Norton.

Fahlberg, V. (2012). A child's journey through placement. ( $2^{\text {nd }}$ ed.). London, United Kingdom: Jessica Kingsley Publishers.

Ferguson, H. (2010). 'Walks, home visits and atmospheres: risk and the everyday practices and motilities of social work and child protection.' British Journal of Social Work, 40, 1100-1117. Goodley, D. (2013) 'Why Critical Disability Studies?' in Ogden, C.A., and Wakeman, S. (eds) Corporeality: The Body and Society Chester, University of Chester Press

Henderson, J., and Forbat, L. (2002) 'Relationship-based social policy: personal and policy constructions of care' Critical Social Policy 22(4): 669-687. 
HM Government. (2013). Working together to safeguard children, a guide to inter-agency working to safeguard and promote the welfare of children. Nottingham, United Kingdom: DSCF.

Holland, S. (2011). Child and family assessment in social work practice. (2nd ed.). London, United Kingdom: SAGE.

Horwath, J. (2010). The child's world, assessing children in need. (2 ${ }^{\text {nd }}$ ed.). London, United Kingdom: Jessica Kingsley Publishers.

Horwath, J. (2011) 'See the Practitioner, See the Child: The Framework for the Assessment of Children in Need and their Families Ten Years On' in British Journal of Social Work. 41 (6): 1070-1087

Kirton, D. (2009). Child social work policy and practice. London, United Kingdom: SAGE.

Knight, A., Clarke, A., Petrie, P., \& Statham, J. (2006). The views of children and young people with learning disabilities about the support they receive from social services: a review of consultations and methods. London, United Kingdom: Thomas Coram Research Unit.

Lefevre, M. (2013). 'Becoming effective communicators with children: developing practitioner capability through social work education'. British Journal of Social Work, 1-21.

Lishman, J. (2009). Communication in social work. (2nd ed.). Basingstoke, United Kingdom: Palgrave Macmillan.

Lundy, L., and McEvoy, L. (2012) 'Children's rights and research processes. Assisting children to (in)formed views.' Childhood, 19, 129-144.

Miller, D., and Brown, J. (2014) We have the right to be safe: Protecting disabled children from abuse London, NSPCC 
Morris, J. (2005). Children on the edge of care: Human rights and the Children Act. United Kingdom, London: Joseph Roundtree Foundation.

Munro, E. (2011). The Munro review of child protection: final report: A child-centred system. London, United Kingdom: Department for Education.

Murray, P. (2000) 'Disabled children, parents and professionals: Partnership on whose terms? Disability and Society 15 (4): 683-698.

Ofsted. (2012). Protecting disabled children: thematic inspection. London, United Kingdom: OFSTED.

Oliver, M. (2013) 'The social model of disability: thirty years on', Disability \& Society, 28:7, 1024-1026

Olli, J., Vehkakoski, T., and Salantera, S. (2012) 'Facilitating and hindering factors in the realisation of disabled children's agency in institutional contexts: literature review' Disability and Society 27: 6: 793-807

Parton, N. (2014) The politics of child protection: Contemporary developments and Future Directions Basingstoke, Palgrave Macmillan.

Read, J., Clements, L., \& Ruebain, D. (2009). Disabled children and the law, research and good practice. ( $2^{\text {nd }}$ ed.). London, United Kingdom: Jessica Kingsley Publishers.

Richards, S., Sullivan, M.P., Tanner, D., Beech, C., Milne, A., Ray, M., Phillips, J., and Lloyd, L. (2013) 'On the Edge of a New Frontier: Is Gerontological Social Work in the UK Ready to Meet Twenty-First-Century Challenges?' British Journal of Social Work Advanced access: May $10^{\text {th }}$ 
Singh,V. and Ghai, A. (2009) 'Notions of Self: Liver Realities of Children with Disability' Disability and Society 24(2): 129-145.

Smith, P. (2009). Disabled children and the children act 1989. Journal of children's services, 5(3), 61-68.

Smith, R. (2009). Doing social work research. Berkshire, United Kingdom: Open University Press.

Smith, J., Flowers, P., \& Larkin, M. (2009). Interpretative phenomenological analysis: theory, method and research. London, United Kingdom: SAGE.

Stein, M. (2009). Quality matters in children's services: messages from research. London, United Kingdom: Jessica Kingsley Publishers.

Taylor, J., Cameron, A., Jones, C., Franklin, A., Stalker, K., and Fry, D. (2015) Deaf and disabled children talking about child protection Edinburgh, University of Edinburgh/NSPCC

Thomas, C. (1999) Female Forms: Experiencing and Understanding Disability Open University Press

Thomas, C. (2007) Sociologies of Disability and Illness: Contested Ideas in Disability Studies and Medical Sociology Basingstoke, Palgrave MacMillan

Thorne, S. (2016) Interpretive Description: Qualitative Research for Applied Research $2^{\text {nd }}$ Edition Abingdon, Routledge

Wall, J. (2012). 'Can democracy represent children? Toward a politics of difference'. Childhood, 19(1), 86-100. 
Ward, H., Skuse, T., \& Munro, E. (2005). 'The best of times, the worst of times: young people's views of care and accommodation'. Adoption and Fostering, 29(1), 8-17.

Watson, N. (2012) 'Theorising the Lives of Disabled Children: How Can Disability Theory Help?' Children and Society 26 (3): 192-202

Webb, S.A. (2006) Social Work in a Risk Society Basingstoke, Palgrave MacMillan.

Woodcock, J., \& Tregaskis, C. (2008). 'Understanding structural and communication barriers to ordinary family life for families with disabled children: A combined social work and social model of disability analysis'. British Journal of Social Work; 38, 55-71.

World Health Organization (2013) Ten facts on disability; Webpage. Available from: http://www.who.int/features/factfiles/disability/en/. Accessed April 12/02/2016.

Worsely, A., Mann, T., Olsen., \& Mason-Whitehead, E. (2013). Key concepts in social work practice. London, United Kingdom: SAGE.

Wyse, D. (2004). Childhood studies: an introduction. London, United Kingdom: Blackwell Publishing.

Young, A.M., Hunt, R., and Smith, C. (2008) The impact of integrated Children's services on the scope, delivery and quality of social care services for deaf children and families - Phase 1 report. London, NCDS 
